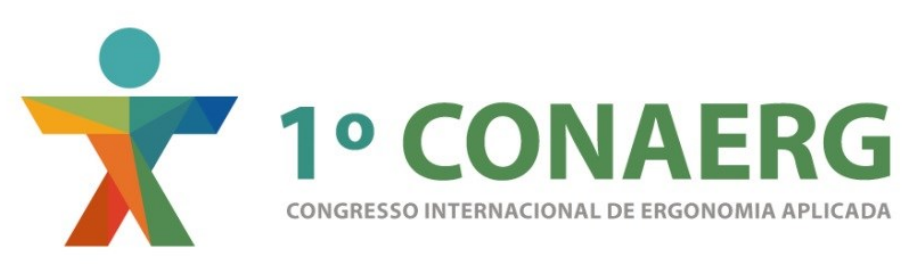

\title{
ASPECTOS ERGONÔMICOS E AVALIAÇÃO DA VIBRAÇÃO NOS MEMBROS SUPERIORES NOS OPERADORES DE MOTOCULTIVADOR
}

\author{
Victor Manieri Schutzer (1); \\ João Eduardo Guarnetti dos Santos (2); \\ Bento Rodrigues de Pontes Junior (3).
}

(1) Universidade Paulista “Júlio de Mesquita Filho", Mestrando em Engenharia Mecânica victor_schutzer@hotmail.com

(2) Universidade Paulista "Júlio de Mesquita Filho", Doutorado em Agronomia guarneti@feb.unesp.br

(3) Universidade Paulista “Júlio de Mesquita Filho”, Doutorado em Engenharia Elétrica brpontes@feb.unesp.br

\begin{abstract}
RESUMO
No Brasil, há diversos problemas de ordem ocupacional e operacional considerando-se a utilização de máquinas e equipamentos agrícolas, principalmente quando se refere aos utilizados na agricultura familiar. Com base nos riscos que operadores de equipamentos mecânicos estão expostos quando se refere à vibração, analisou-se a vibração nas mãos de operadores de um motocultivador que estão expostos nas atividades de trabalho. Nesse estudo, utilizou-se um acelerômetro triaxial HVM-100, marca Larson Davis. Para avaliação e análise dos resultados utilizou-se a norma ISO 5349:2001 e Diretiva Europeia 2002/44/EC. Os resultados apresentados mostraram a importância dos testes realizados e da correta utilização de EPIs.
\end{abstract}

\begin{abstract}
In Brazil, there are several problems of occupational and operational order considering the use of agricultural machinery and equipment, especially when it comes to those used in family-based agriculture. Based on the risk that mechanical equipment operators are exposed to when it comes to vibration, we analyzed the hand vibrations from operators who use power tillers during work. In this study, we used a triaxial accelerometer HVM-100, Larson Davis brand. For assessment and analysis of the results we used the ISO 5349:2001 and European Directive 2002/44/EC. The results showed the importance of the tests and the correct use of PPE.
\end{abstract}

\section{INTRODUÇÃO}

O conforto humano tornou-se aspecto fundamental quando se trata da interação entre ser humano e equipamentos mecânicos. A relação entre homem e a máquina, ou seja, a adaptação do trabalho ao homem é o objetivo do estudo da ergonomia (IIDA, 2016). Podese definir Ergonomia como "uma disciplina científica relacionada ao entendimento das 
interações entre os seres humanos e outros elementos ou sistemas, e à aplicação de teorias, princípios, dados e métodos a projetos a fim de otimizar o bem-estar humano e o desempenho global do sistema. Os ergonomistas contribuem para o planejamento, projeto e a avaliação de tarefas, postos de trabalho, produtos, ambientes e sistemas de modo a tornálos compatíveis com as necessidades, habilidades e limitações das pessoas." (IEA, 2000). Uma dessas interações, que a ergonomia busca entendimento, é a exposição do ser humano à vibração advindas de vários tipos de excitações mecânicas.

É importante, primeiramente, definir o que é vibração. Rao (2008) define vibração como um movimento que se repete após um intervalo de tempo. Ainda segundo o mesmo autor, a maioria dos motores de acionamento possuem problemas de vibração por conta do desbalanceamento inerente a esse tipo de equipamento e, em muitos casos, o ser humano age como parte integral do sistema causando, assim, desconforto e prejuízo para o corpo humano. De acordo com Tosin (2009), as vibrações são fatores que causam doenças e que afastam trabalhadores de suas funções e apresentam grande influência na qualidade final em operações agrícolas que utilizam máquinas. Segundo Gerges (2000), a vibração no corpo humano pode ocasionar sérias doenças, como por exemplo: danos permanentes em órgãos internos, perda de equilíbrio, visão turva e falta de concentração. Vendrame (2006) explica que o corpo humano possui uma vibração natural e se uma frequência externa coincidir com a frequência natural do sistema, ocorre a ressonância, que implica em amplificação do movimento. Pode-se visualizar as diferentes frequências naturais do corpo humano na Figura 1.

Figura 1. Frequências naturais de diferentes partes do corpo humano.

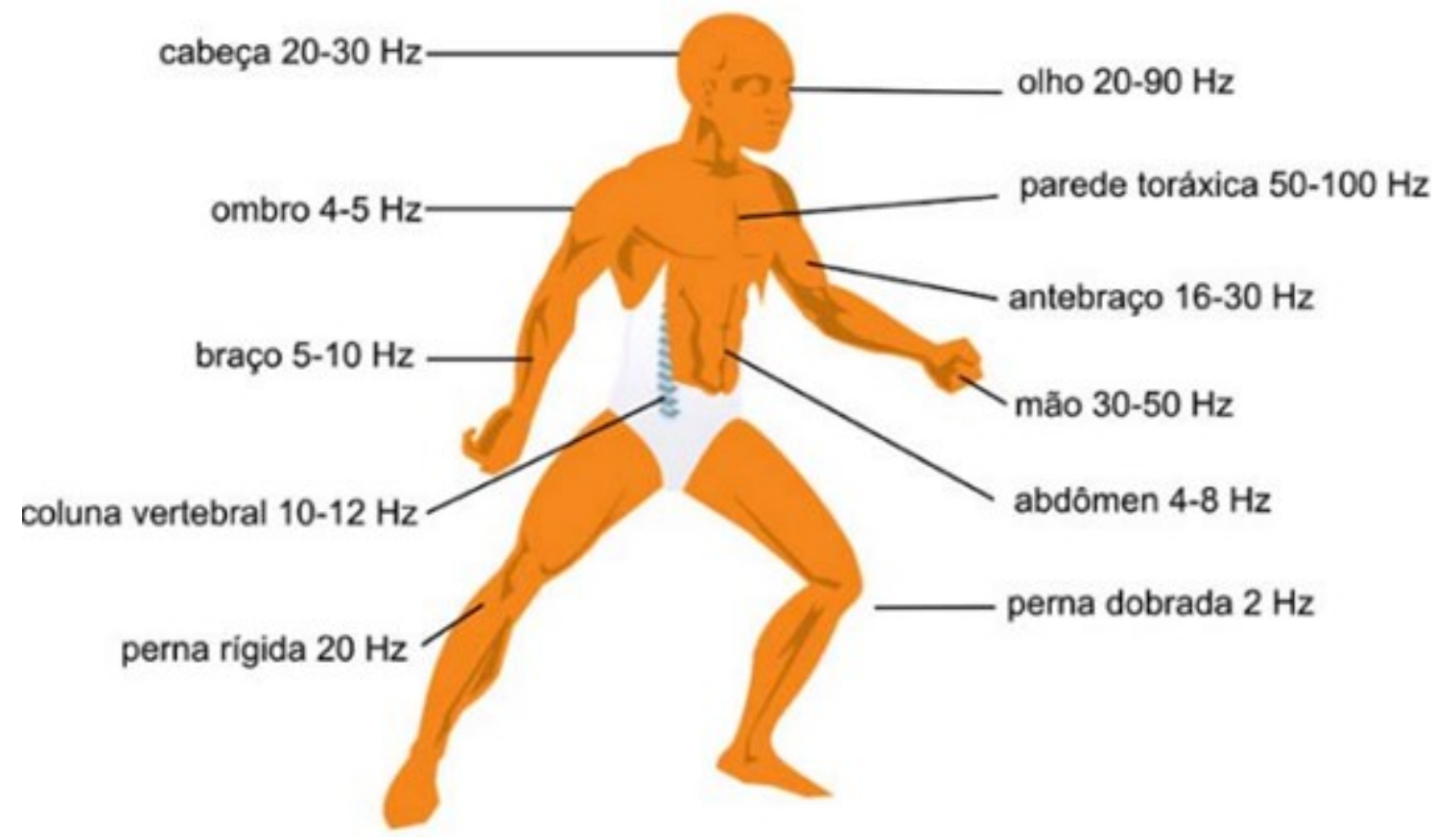

Fonte: Vendrame (2006).

Mais especificamente para vibrações em mãos e braços, Vendrame (2006) cita que a faixa de frequência se situa entre 6,3 a $1250 \mathrm{~Hz}$, ocorrendo nos trabalhos com ferramentas manuais. De acordo com Braga (2007), os níveis de vibração encontrados em algumas ferramentas manuais são suficientemente elevados para causar danos quando operados por longos períodos de tempo. Para níveis baixos de vibração haverá desconforto e redução da eficiência do trabalho e para altos níveis e longos períodos de exposição, poderá ocorrer doenças que afetam os vasos sanguíneos e a circulação. Uma dessas doenças é a patologia popularmente conhecida como "Dedos Brancos" que, segundo Kroemer e 
Grandjean (2005), são causadas por ferramentas motorizadas com frequência entre 40 e $300 \mathrm{~Hz}$. Ainda segundo o mesmo autor, as vibrações são rapidamente amortizadas nos tecidos, gerando um efeito danoso nos vasos sanguíneos e nervos das mãos, resultando no amortecimento dos sentidos de um ou mais dedos tornando-se, dessa forma, branco, frio e sem sensações. Pode-se visualizar um dos efeitos da patologia na Figura 2.

Figura 2. Patologia "Dedos Brancos".

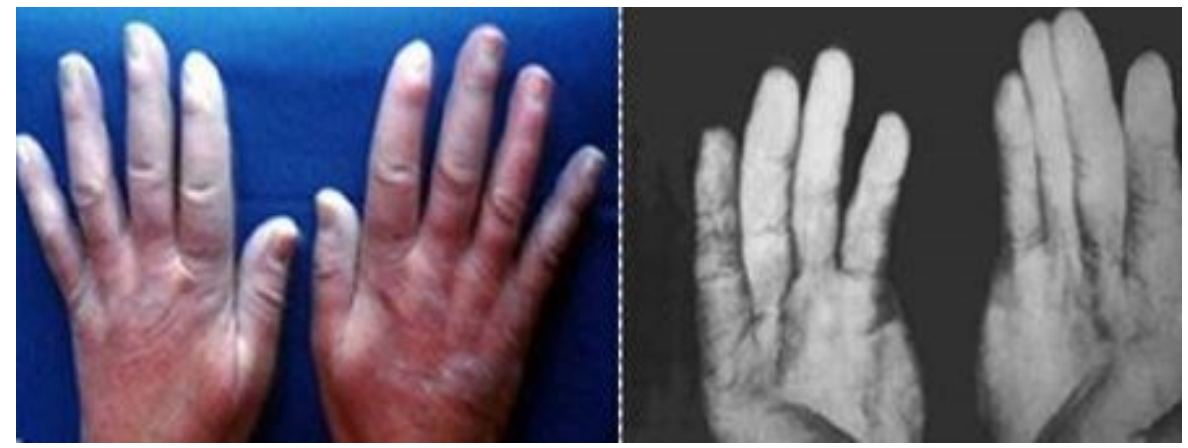

Fonte: Syndrome Vibration NIOSH (1998).

Percebe-se, então, a importância do estudo realizado para que se tenha conhecimento do tempo de exposição à vibração na operação de motocultivador e, assim, não haja prejuízo à saúde do operador a curto, médio e longo prazo.

\section{NORMAS PARA VIBRAÇÃO EM MÃOS E BRAÇOS}

Os procedimentos utilizados para os testes e análise dos resultados estão de acordo com a norma internacional ISO 5349:2001 - partes 1 e 2 (Vibração Mecânica - Medição, Avaliação da Exposição Humana da Vibração Transmitida à Mão) e com a Diretiva Europeia 2002/44/EC. Primeiramente, é necessário que o acelerômetro esteja fixado de forma que não atrapalhe o manuseio do equipamento mecânico e que obedeça ao sistema de coordenadas, como é possível visualizar através da Figura 3.

Figura 3. Sistema de coordenadas para mãos e braços.
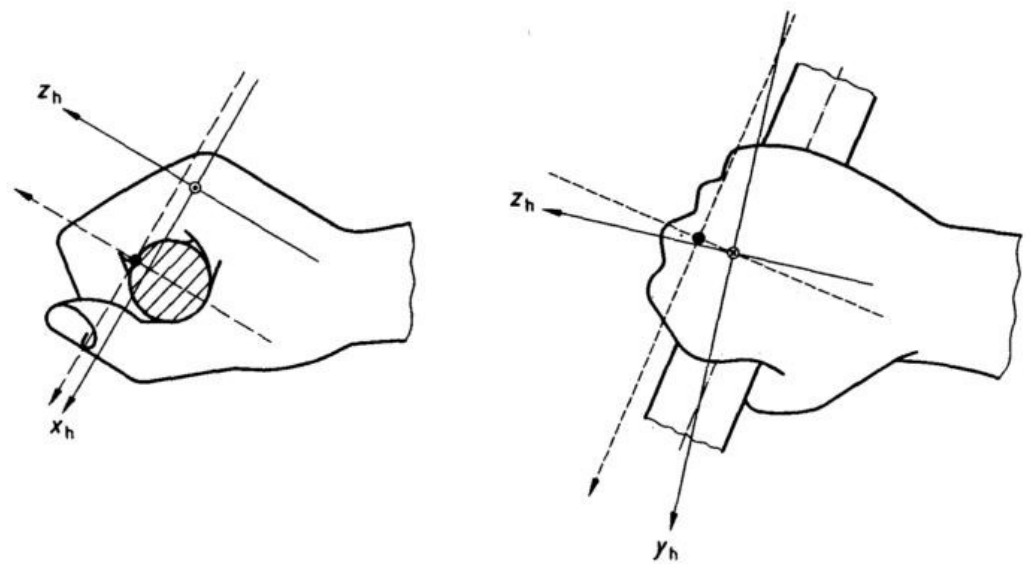

Fonte: ISO 5349 (2001).

Para análise da intensidade e de exposição à vibração tem-se, segundo a ISO 5349 (2001), a Equação 1 e 2 para A(8) e Dy, respectivamente. 
$\mathrm{A}(8)=\mathrm{anv}_{\mathrm{nv}} \sqrt{\frac{T}{T_{0}}}$

[Eq. 01]

Onde:

A(8) - projeção de dose para 8 horas;

$a_{\text {hv }}$ - valor de aceleração da vibração transmitida à mão (raiz média quadrática dos componentes $x$, y e $z)$, em metros por segundo ao quadrado $\left(\mathrm{m} / \mathrm{s}^{2}\right)$ e rms;

T - duração total para a exposição da vibração anv;

To - duração referente a 8 horas (28800s).

$D_{y}=31,8[A(8)]^{-1,06}$

[Eq. 02]

Onde:

$D_{y}$ - Tempo (anos) para $10 \%$ do grupo apresentar "dedos brancos".

É possível, ainda, a análise do tempo para aparecimento dos "dedos brancos" através da Figura 4.

Figura 4. Tempo para aparecimento de "dedos brancos".

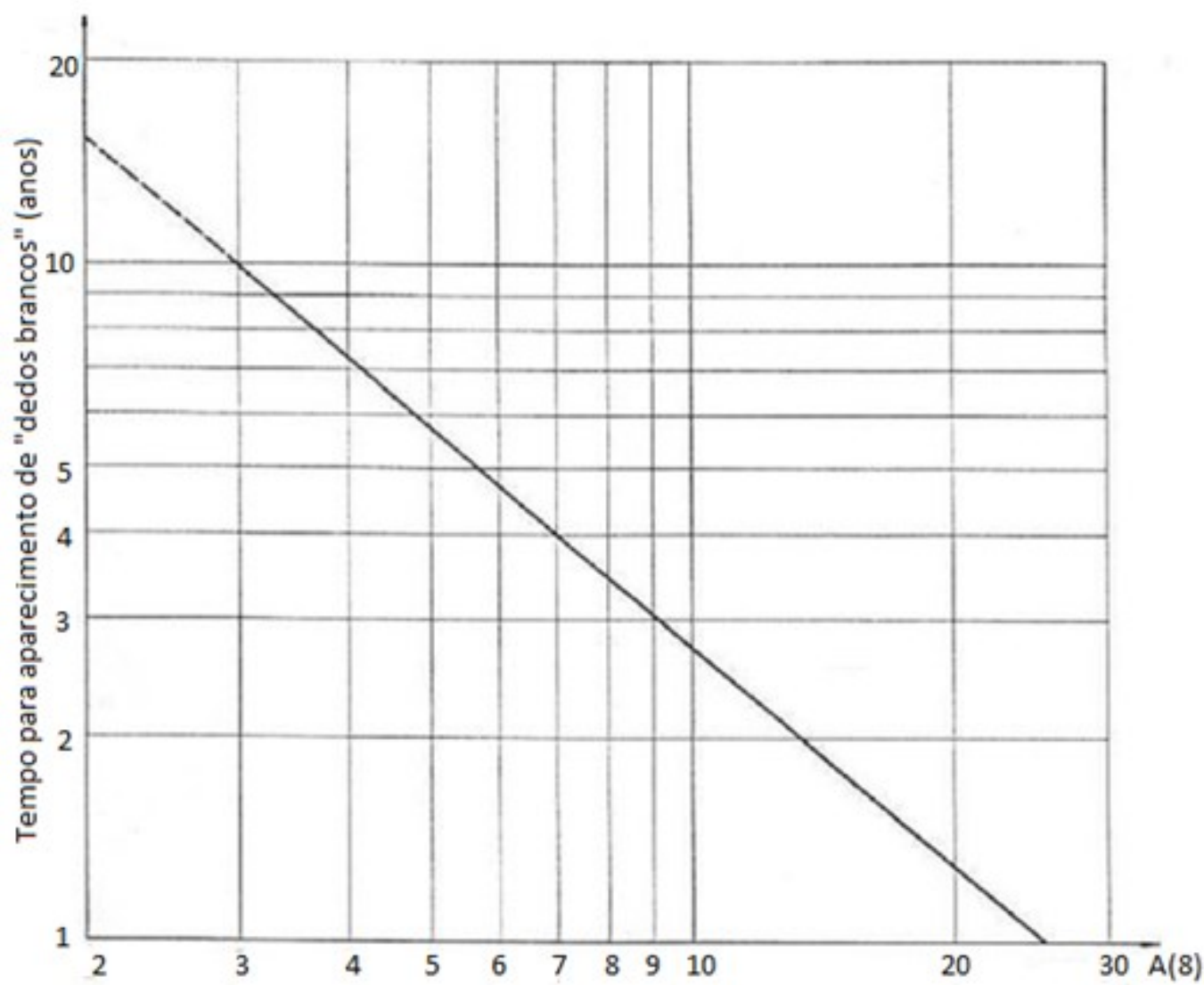

Fonte: Modificado da ISO 5349 (2001).

Em complemento com a ISO 5349 (2001), a Diretiva Europeia 2002/44/EC (2002) estabelece os seguintes níveis de exposição para vibração em mãos em braços, como pode ser visualizado na Tabela 1. 
Tabela 1. Nível de Ação e Limite de Exposição.

\begin{tabular}{|c|c|}
\hline $\mathbf{A}(8)$ & Classificação \\
\hline $2,5 \mathrm{~m} / \mathrm{s}^{2}$ & Nível de Ação \\
\hline $5,0 \mathrm{~m} / \mathrm{s}^{2}$ & Limite de Exposição \\
\hline
\end{tabular}

Fonte: Diretiva Europeia 2002/44/EC (2002).

\section{OBJETIVO}

O objetivo do presente trabalho foi mensurar e analisar a vibração que é transmitida para a mão do operador de motocultivador de acordo com a ISO 5349 (2001) e, também, avaliar o tempo de exposição à vibração para que não ocorra prejuízo à saúde do operador (Nível de Ação) e o tempo máximo de exposição até que atinha o Limite de Exposição proposto pela Diretiva Europeia 2002/44/EC (2002).

\section{MATERIAIS E MÉTODOS}

Para mensurar a vibração, utilizou-se um acelerômetro triaxial (x, y e z) HVM-100, marca Larson Davis. O dispositivo permite configuração independente de cada eixo de acordo com o manual do usuário e bibliografias correlatadas. O acelerômetro pode ser visualizado na Figura 5.

Figura 5. Acelerômetro HVM-100.

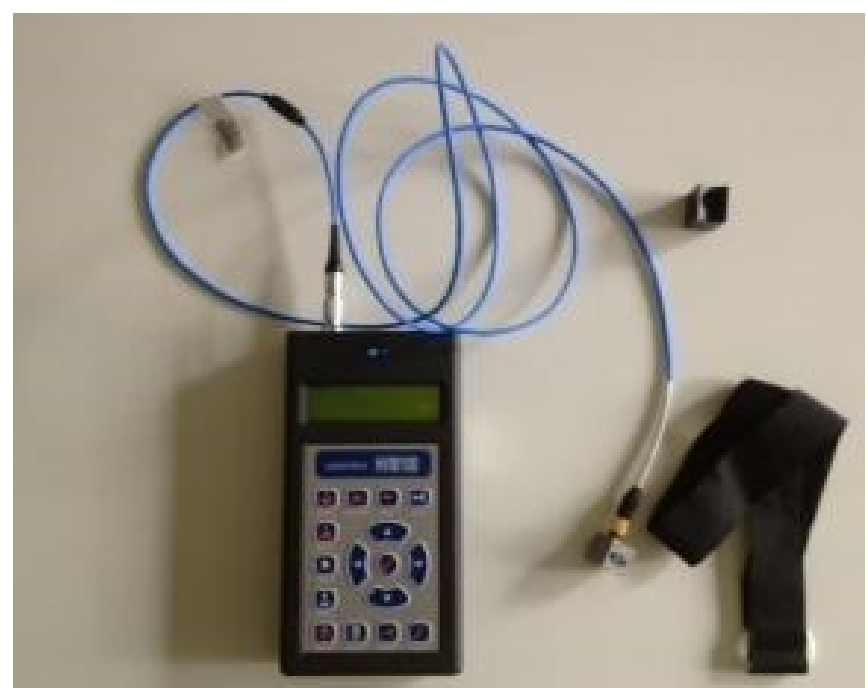

Utilizou-se um adaptador do tipo Barra para análise da vibração, adaptador este que fica posicionado junto à palma da mão conforme prevê a ISO 5349 (2001). O acelerômetro juntamente com o adaptador é montado para que os eixos $\mathrm{x}$, y e $\mathrm{z}$ sejam respeitados conforme a ISO 5349 (2001).

Foi utilizado um motocultivador pertencente à UNESP-Bauru e, para os testes em movimento, utilizou-se sulcador, implemento utilizado para abrir sulcos no solo para 
posterior plantio de sementes ou mudas. Pode-se visualizar motocultivador e o implemento na Figura 6.

Figura 6. Motocultivador e sulcador acoplado à haste de apoio.

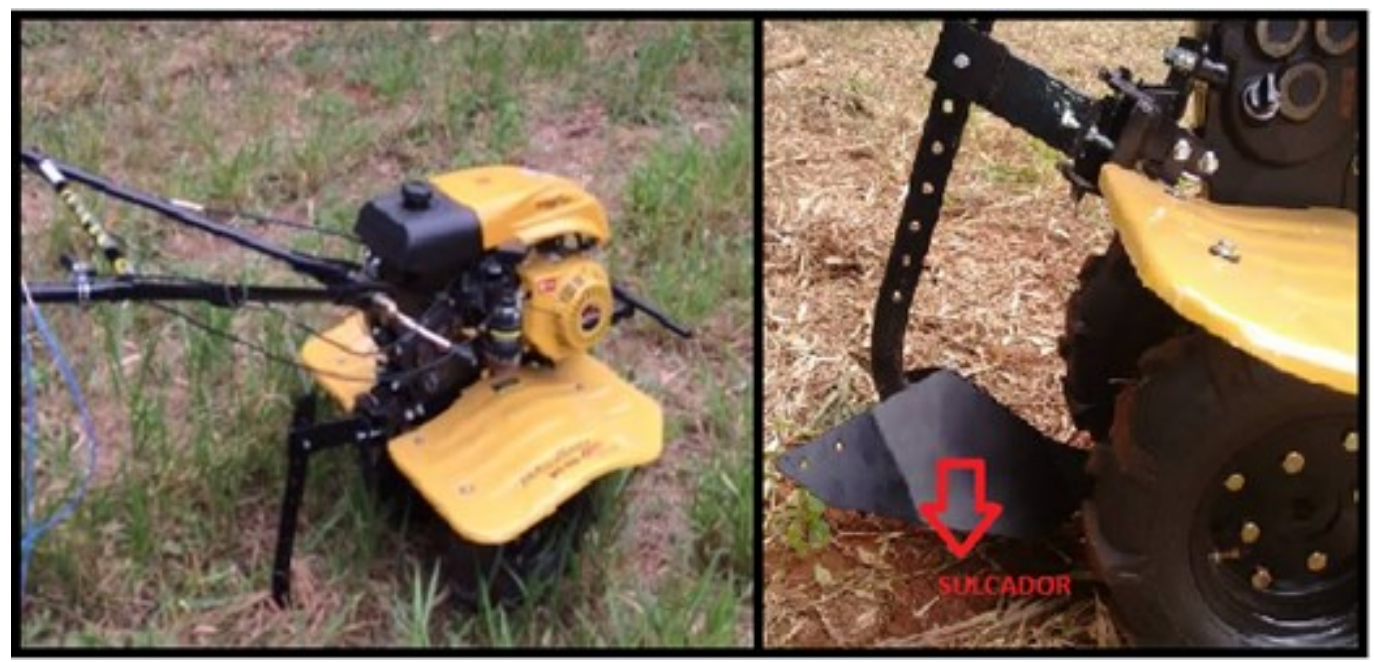

Para análise da vibração nas mãos e braços, adotou-se os procedimentos estabelecidos pela norma internacional ISO 5349:2001 (Vibração Mecânica - Medição, Avaliação da Exposição Humana da Vibração Transmitida à Mão). Para análise dos resultados, adotou-se a Diretiva Europeia que estabelece o Nível de Ação e Limite de Exposição.

O HVM-100 foi calibrado de acordo com o manual do fabricante e bibliografias correlatadas. $\mathrm{O}$ acelerômetro foi configurado para operar no modo mãos e braços, curva Wh (limitado pela banda 6,3 a $1250 \mathrm{~Hz}$ ), fatores multiplicativos de 1,0 para os eixos $x, y$ e $z$, saída com AC Ponderado, sem ganho e sensibilidade de acordo com a carta do fabricante. A Figura 7 apresenta a curva de ponderação por frequência Wh.

Figura 7. Curva de ponderação por frequência Wh para vibração em mãos e braços.

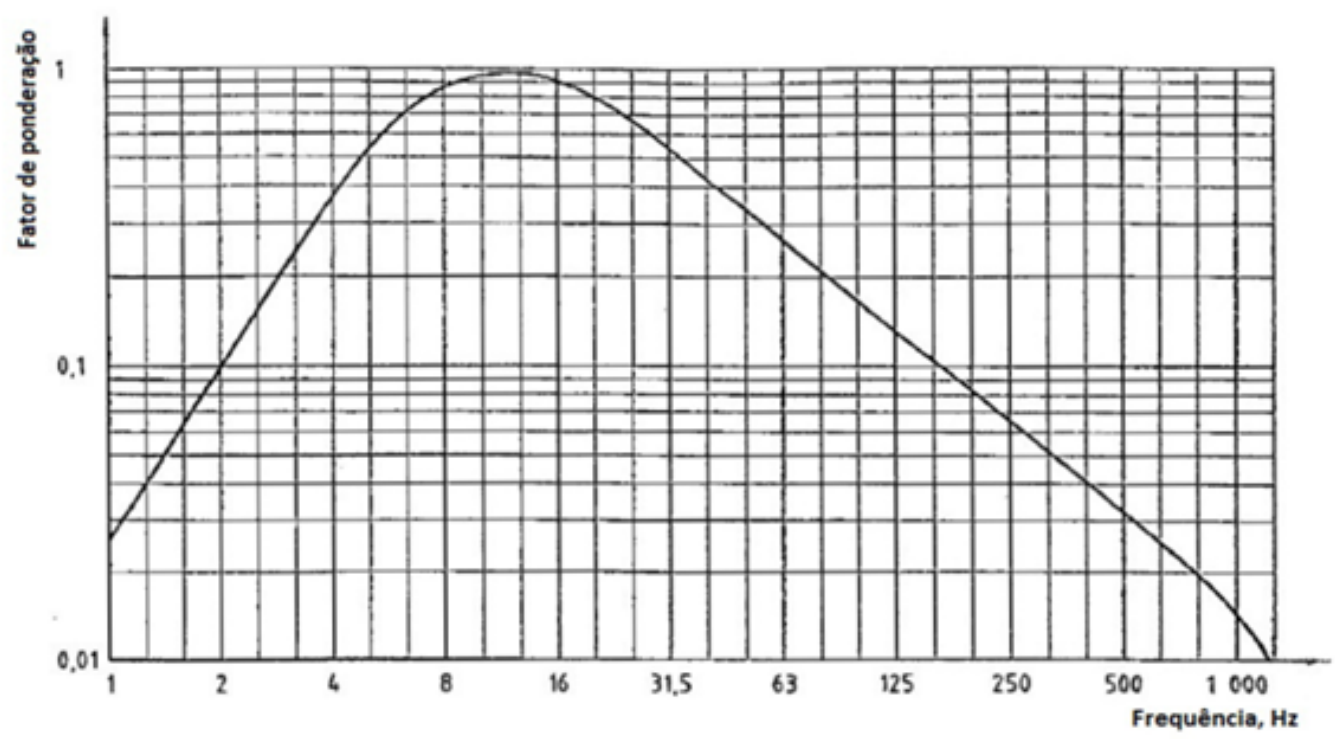

Fonte: ISO 5349 (2001).

O tempo de medição para cada teste realizado foi de um minuto, com isso o acelerômetro forneceu sessenta dados de aceleração (um dado em rms a cada segundo) para os eixos $\mathrm{x}$, 
y e z e para o vetor Soma. A fixação do acelerômetro se deu através de um adaptador do tipo Barra e colocado junto à mão do operador, respeitando os eixos de coordenadas conforme prevê a ISO 5349 (2001).

Os testes foram realizados com o motocultivador parado, com baixa e alta rotação, e em movimento utilizando o sulcador, com $1^{\mathrm{a}}$ e $2^{\mathrm{a}}$ marcha lenta e $1^{\mathrm{a}}$ e $2^{\mathrm{a}}$ marcha acelerada, de acordo com o manual do fabricante. Os testes foram realizados em uma pista de vinte metros, com condições operacionais de topografia plana, solo Arenito Bauru e vegetação de braquiária. Utilizou-se um único operador para o motocultivador para que não houvesse mudanças significativas nos testes. As sequências dos testes realizados podem ser visualizadas na Tabela 2. Para cada teste, realizou-se três repetições para obtenção da média. Os autores desse trabalho foram os responsáveis pela operação do motocultivador durante os testes.

Tabela 2. Sequência de testes realizados.

\begin{tabular}{|c|c|}
\hline Teste & Especificações \\
\hline Teste 1 & Estático e em baixa rotação \\
\hline Teste 2 & Estático e em alta rotação \\
\hline Teste 3 & Dinâmico e 1 1a marcha lenta \\
\hline Teste 4 & Dinâmico e 2 ${ }^{\text {a } \text { marcha lenta }}$ \\
\hline Teste 5 & Dinâmico e 1 1a marcha acelerada \\
\hline Teste 6 & Dinâmico e 2 2 marcha acelerada \\
\hline
\end{tabular}

\section{RESULTADOS E DISCUSSÃO}

Os resultados dos testes com o motocultivador podem ser visualizados na Tabela 3. Como realizou três repetições para cada teste, utilizou-se a média aritmética de cada repetição como pode-se visualizar através da Tabela 3.

Tabela 3. Resultados dos testes de vibração. 


\begin{tabular}{|c|c|c|c|c|}
\hline Testes & $\begin{array}{c}\text { Repetição 1 } \\
\left(\mathbf{m} / \mathbf{s}^{2}\right)\end{array}$ & $\begin{array}{c}\text { Repetição 2 } \\
\left(\mathbf{m} / \mathbf{s}^{\mathbf{2}}\right)\end{array}$ & $\begin{array}{c}\text { Repetição 3 } \\
\left(\mathbf{m} / \mathbf{s}^{\mathbf{2}}\right)\end{array}$ & $\begin{array}{c}\text { Média } \\
\left(\mathbf{m} / \mathbf{s}^{\mathbf{2}}\right)\end{array}$ \\
\hline Teste 1 & 13,24 & 13,29 & 12,49 & 13,01 \\
\hline Teste 2 & 22,94 & 23,16 & 24,85 & 23,65 \\
\hline Teste 3 & 3,80 & 3,75 & 3,71 & 3,75 \\
\hline Teste 4 & 5,35 & 5,40 & 5,05 & 5,27 \\
\hline Teste 5 & 7,64 & 7,60 & 8,00 & 7,75 \\
\hline Teste 6 & 9,01 & 8,66 & 8,71 & 8,79 \\
\hline
\end{tabular}

Através da Tabela 3, percebe-se que os testes com o motocultivador parado obtiveram maiores níveis de vibração, principalmente o teste com o equipamento em alta rotação do motor. Já os testes com o motocultivador em movimento e utilizando o sulcador, apresentaram maiores níveis de vibração conforme o aumento da velocidade e da rotação do motor.

Posteriormente, calculou-se, a partir da Equação 1, o tempo que o operador pode estar exposto, para uma jornada de trabalho de 8 horas diárias, sem que haja prejuízo à saúde, ou seja, o tempo até que atinja o Nível de Ação $\left(2,5 \mathrm{~m} / \mathrm{s}^{2}\right)$. Calculou-se, também, o tempo máximo de exposição para que a vibração atinja o Limite de Exposição $\left(5,0 \mathrm{~m} / \mathrm{s}^{2}\right)$. Esses limites estão de acordo com a Diretiva Europeia 2002/44/EC (2002) e os resultados podem ser observados na Tabela 4.

Tabela 4. Resultados dos testes de vibração.

\begin{tabular}{|c|c|c|}
\hline Teste & Nível de Ação (horas) & $\begin{array}{c}\text { Limite de Exposição } \\
\text { (horas) }\end{array}$ \\
\hline Teste 1 & 0,30 & 1,18 \\
\hline Teste 2 & 0,09 & 0,36 \\
\hline Teste 3 & 3,56 & 14,22 \\
\hline Teste 4 & 1,80 & 7,20 \\
\hline
\end{tabular}




\begin{tabular}{|c|c|c|}
\hline Teste 5 & 0,83 & 3,33 \\
\hline Teste 6 & 0,65 & 2,59 \\
\hline
\end{tabular}

Percebe-se, através da Tabela 4, que o tempo para que não haja prejuízo à saúde do operador (Nível de Ação) não atingiu ou ultrapassou, em nenhum teste, as 8 horas diárias de trabalho, isso significa que o operador deve ficar atento para que o tempo não ultrapasse o Nível de Ação proposto pela Diretiva Europeia 2002/44/EC. Já o tempo para atingir o Limite de Exposição ultrapassou as 8 horas diárias de trabalho apenas para o teste com o motocultivador em movimento e com $1^{\mathrm{a}}$ marcha lenta, e chegou próximo as 8 horas para 0 teste com motocultivador em movimento e com $2^{\mathrm{a}}$ marcha lenta.

Para um melhor entendimento e visualização da vibração durante o período dos testes, gerou-se gráficos das vibrações ao longo da análise de um minuto para cada repetição e teste realizado. Primeiramente, comparou-se a análise da vibração com o motocultivador parado, como pode ser visualizado através da Figura 8.

Figura 8. Vibração gerada com o motocultivador parado.

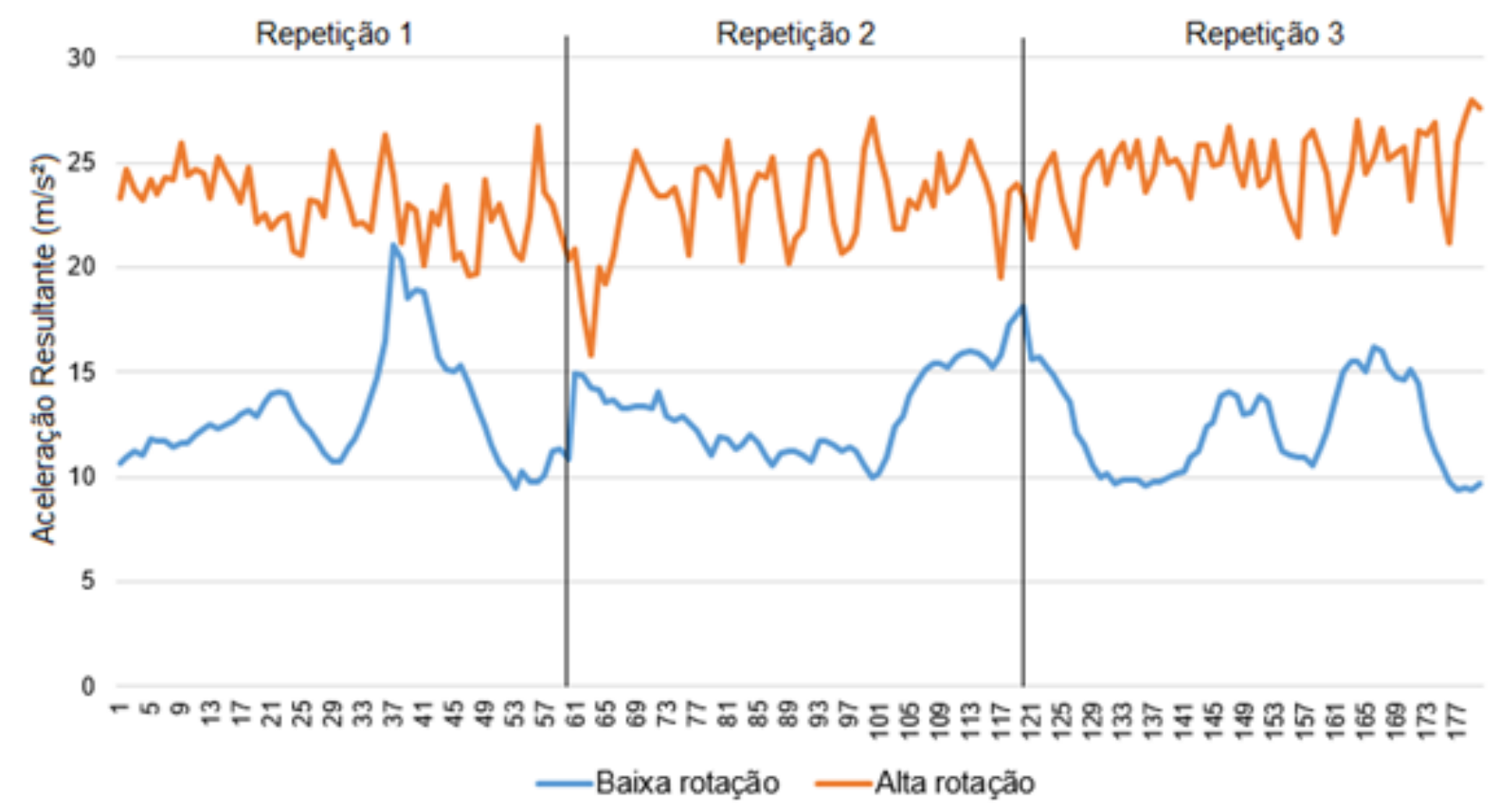

Já a Figura 9 apresenta a vibração das repetições para cada um dos testes que foram realizados com o motocultivador em movimento e utilizando o sulcador.

Figura 9. Vibração gerada com o motocultivador em movimento. 


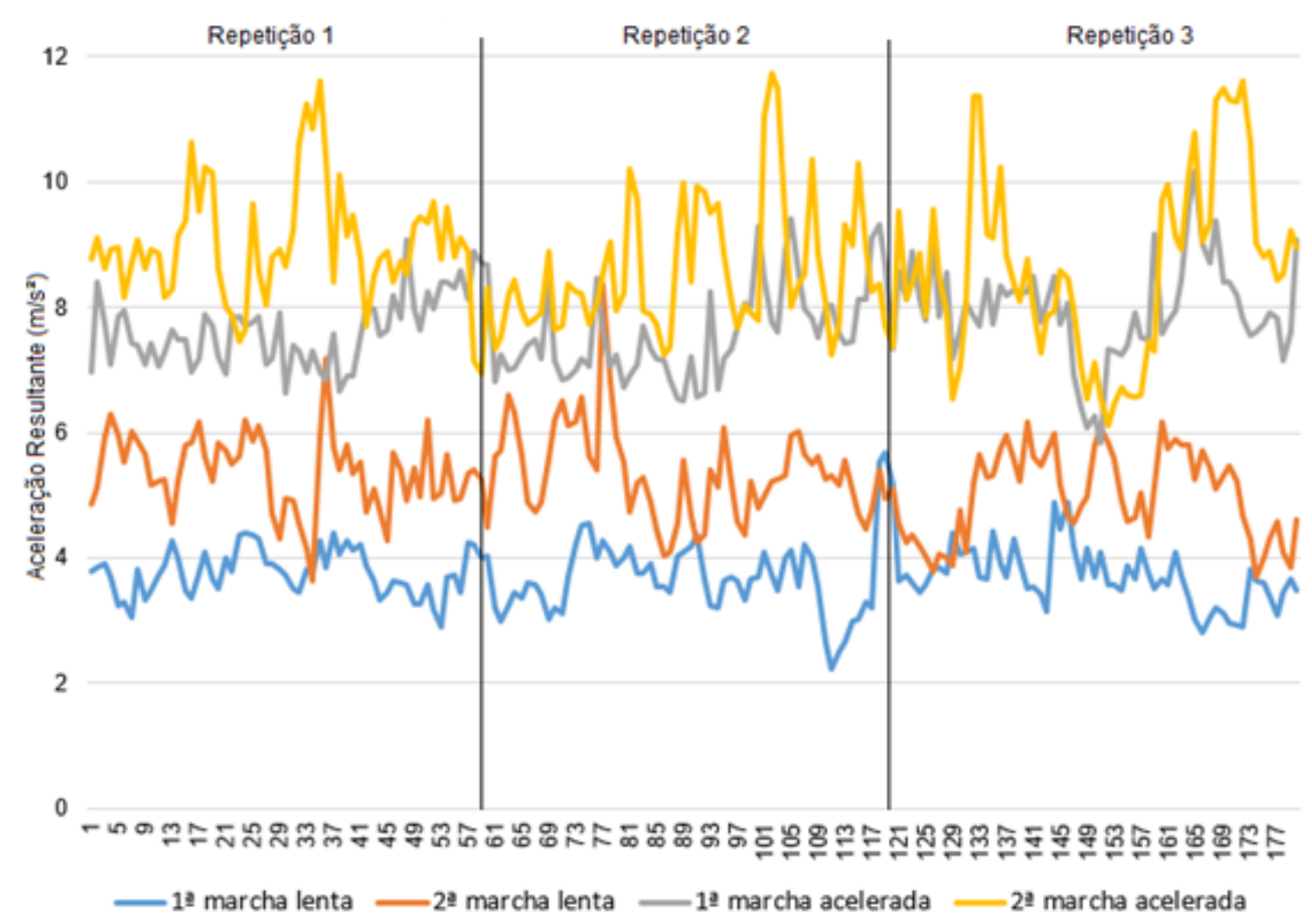

\section{CONCLUSÃO}

Através dos resultados obtidos no presente trabalho, conclui-se que é de extrema importância a utilização de luvas para que se minimize a vibração captada pela mão do operador e, consequentemente, possa operar por mais tempo o motocultivador de acordo com o que preconiza a ISO 5349 (2001) e a Diretiva Europeia 2002/44/EC. Outro fator de extrema importância para a intensidade da vibração gerada é a velocidade durante a operação com o motocultivador pois, velocidades e rotações mais altas apresentaram maiores intensidades de vibração transmitida à mão do operador. Portanto, recomenda-se a utilização de velocidades mais baixas e marchas reduzidas durante a operação desse tipo de equipamento.

Com isso, é importante que empregadores e empregados estejam atentos à ISO 5349 (2001) e à Diretiva Europeia (2002) para que os operadores de equipamentos mecânicos que transmitem vibrações às mãos não ultrapassem o tempo de exposição e, dessa forma, não tenha a saúde prejudicada no decorrer das atividades laborais.

\section{REFERÊNCIAS BIBLIOGRÁFICAS}

BRAGA, C. A. C. Exposição Ocupacional a Vibrações no Sistema Mão-Braço no Sector da Construção. 2007. Tese (Mestrado em Engenharia de Segurança e Higiene Ocupacionais), Faculdade de Engenharia da Universidade do Porto, 2007.

DIRETIVA EUROPEIA 2002/44/EC - Parlamento Europeu e Conselho da União Europeia de 25/06/2002. Jornal Oficial da Comunidade Europeia de 06/07/2002, L 177. p.13-19, 2002.

GERGES, S. N. Y. Ruído: Fundamentos e controle. 2. ed. Florianópolis: Nr Editora, 2000.

IEA - International Ergonomics Association, 2000. Disponível em: http://www.iea.cc/whats/index.html Acesso em 13/06/2016. 
IIDA, I. Ergonomia: Projeto e Produção. 3a . ed. revista São Paulo: Edgard, Blucher, 2016.

ISO 5349 - Mechanical vibration - measurement and evaluation of human exposure to hand transmitted vibration. Part 1: General requirements. Part 2: Practical guidance for measurement at the workplace. Genebra, 2001.

KROEMER, K. H. E., GRANDJEAN, E. Manual de Ergonomia: Adaptando o trabalho ao homem. 5. ed., Porto Alegre: Artmed, 2005.

$\mathrm{NIOSH}$ - National Institute for Occupational Safety and Health. Preventing Occupational Hearing Loss. A Practical Guide. Cincinnati, Ohio,1998.

RAO, S. Vibrações Mecânicas. 4ª.ed. São Paulo: Pearson Prentice Hall, 2008.

TOSIN, R. C. Avaliação do ruído e da vibração no posto de trabalho em dois tratores agrícolas. 2009. Tese (Doutorado em Energia na Agricultura) - Faculdade de Ciências Agronômicas da UNESP, Campus de Botucatu, 2009.

VENDRAME, A. C.. Vibração ocupacional. 2006. Disponível em < http://www.higieneocupacional.com.br/download/vibracoes_vendrame.pdf> Acesso em 13/06/2016.

\section{AGRADECIMENTOS}

Agradece-se ao CNPq pela oportunidade de aquisição do acelerômetro HVM-100 que foi utilizado no presente trabalho. 